\title{
Guest editorial: digital enterprise technology
}

\author{
George Q. Huang • T. Qu • Yingfeng Zhang • \\ Paul G. Maropolous
}

Received: 3 December 2010 / Accepted: 13 December 2010 / Published online: 1 January 2011

(C) The Author(s) 2010. This article is published with open access at Springerlink.com

\begin{abstract}
Digital Enterprise Technology (DET) is "the collection of systems and methods for the digital modelling and analysis of the global product development and realisation process in the context of lifecycle management". The international conference series of Digital Enterprise Technology aims to provide a forum for academia and industrialists to disseminate, to all branches industries and businesses, information and knowledge on the most recent and relevant innovations, theories and practices in electronic business and digital enterprise technology. The 6th CIRP-Sponsored International Conference of Digital Enterprise Technology (DET2009) was held on 14-16 December 2009 at The University of Hong Kong. This special issue consists of 8 or 9 papers best papers selected from those presented at DET2009. These papers cover a set of issues concerning some recent important research and application developments of digital enterprise technologies, forming the broad basis of research agenda to identify and explore the ways in which digital enterprise technologies can facilitate the users and their actions.
\end{abstract}

\section{G. Q. Huang $(\bowtie) \cdot T$. Qu}

Department of Industrial and Manufacturing Systems Engineering, The University of Hong Kong, Hong Kong,

People's Republic of China

e-mail: gqhuang@hku.hk

T. Qu

e-mail: quting@hku.hk

\section{Y. Zhang}

Key Laboratory of Contemporary Design and Integrated Manufacturing Technology, Ministry of Education, Northwestern Polytechnical University, Xi'an, People's Republic of China e-mail: zhangyf@nwpu.edu.cn

P. G. Maropolous

Department of Mechanical Engineering, University of Bath, Bath, UK e-mail: P.G.Maropoulos@bath.ac.uk
The issue begins with a paper entitled "Verification of the Indoor GPS System, by Comparison with Calibrated Coordinates and by Angular Reference" by Muelaner et al. The paper details with their works carried out to verify the dimensional measurement performance of the Indoor GPS (iGPS) system-a network of Rotary-Laser Automatic Theodolites (R-LATs). Initial tests have been carried out to determine the angular uncertainties on an individual R-LAT transmitter-receiver pair. A method is presented of determining the uncertainty of dimensional measurement for a three dimensional coordinate measurement machine. An experimental procedure has been developed to compare three dimensional coordinate measurements with calibrated reference points. The method is found to be practical and able to establish that the expanded uncertainties of the basic and highly optimized version iGPS systems are as less as 1 and $0.25 \mathrm{~mm}$ respectively at a $95 \%$ confidence level.

The paper "Multicriteria Dimensioning of Hard-Finishing Operations regarding Cross-Process Interdependencies" by Denkena and Henning considers the production of high performance metal parts which requires a well balanced multistage process chain on the shop floor for hard-finishing operations. A novel approach based on an a-priori multicriteria dimensioning procedure is introduced to help process planners integrate cross-process interdependencies among multiple stages and reach the overall optimum with balanced settings of process parameters. The results predicted by the Java-implemented prototype software are evaluated by a multistage plunge grinding process for crankshaft journals.

$\mathrm{Qu}$ et al. introduces "A Case of Implementing RFID-Based Real-Time Shop-Floor Material Management for Household Electrical Appliance Manufacturers". This paper contributes to the re-vitalization of RFID efforts in manufacturing industries by presenting a real-life case study of RFID application at a large air conditioner manufacturer. The case study 
discusses how technical, social and organizational issues have been addressed throughout the RFID project and makes the theoretical benefits of RFID such as real-time object visibility and traceability come true in the daily operations of a real-life shop floor. It is hoped that insights and lessons gained be generalized for future efforts across household electrical appliance manufacturers that share similar shop-floor characteristics.

In the paper "RFID-enabled Real-time Manufacturing Information Tracking Infrastructure for Extended Enterprises", Zhang et al. consider the RFID application in an extended enterprise which is composed of multiple individual enterprises. They propose a RFID-enabled real-time manufacturing information tracking infrastructure (RTMITI) to address the real-time manufacturing data capturing and processing for extended enterprises. A series of manufacturing information processing methods has been provided to track and trace the real-time manufacturing information in various levels covering parts/assemblies/products at machines/shop floors/enterprises/extended enterprises. Finally, a case study is given to demonstrate the developed framework and corresponding methodologies.

Fluctuations in demand patterns and products mixes, driven by continuous changes in customer requirements, are inducing significant changes on the operations of manufacturing organizations. How to respond to such changes rapidly and at minimum cost constitutes a major challenge for manufacturers. In the paper "Modelling and Simulation of Dynamically Integrated Manufacturing Systems" Zhang et al., introduce a DIMS project (Dynamically Integrated Manufacturing Systems) in which they develop an agentbased approach that enables manufacturing systems to be modeled using multi-agent systems such that optimal and timely responses to changes are generated from the interactions taking place within the multi-agents systems. This approach also incorporates a distributed discrete event simulation mechanism that enables "what-if" system configurations that have been generated through agent interactions to be evaluated dynamically for system restructure. This paper presents the approach with particular focus on the distributed simulation mechanism.

In the paper "Component Commonality in Closed-Loop Manufacturing System" Su et al., focus on the use of common component in two closed-loop manufacturing structures: parallel and mixed structures, which mean the assembly and disassembly are performed by separate or the same lines. They study the effect of the use of a common component, the location of a common component, and the degree of delayed differentiation on the mean and variance of the cycle time for assembly (CTA).

The paper, "Combining Genetic Approach and Integer Programming to Solve Multi-Facility Economic Lot-Scheduling Problem", by Chan et al. deals with the Economic lot-scheduling problem (ELSP). In contract with the singlefacility ELSP where facility can only produce one single item at a time, multi-facilities ELSP problems deals with the case where many common items are produced in different places in order to satisfy the demands in different markets. However, when more items types to be produced by the facility, the production frequency of each item type will increase because of the balancing of the production rate and the demand rate. Consequently, the number of set-up time and set-up cost increases accordingly. Thus, reallocating the common items, which can be produced in any facilities, to be produced only on certain facility can certainly reduce the number of production frequency, and lead to lower related costs. This paper proposes to divide the main problem into a master problem and sub-problems, which are solved by Integer Programming and Genetic Algorithm respectively. To demonstrate the significance of reallocating the common items and aggregating them to produce in certain facility, several models have been designed, tested and compared. The comparison of the models demonstrates the reduction of the costs benefited by result of common items reallocation.

Seeing the ever higher financial investment required in the manufacturing, delivery and support of service contracts in defence aerospace industry, the paper "A prediction system for assessing customer affordability of whole life cycle cost in defence industry" by Bankole et al. identifies the factors that affect customer affordability of defence contracts and develop an affordability assessment framework which is implemented as a software prototype system. This will enable the customers to maintain the financial ability to procure and support the contract from the conceptual and manufacturing phase to the end of the project given the budget constraints. The developed affordability system has been validated through collaboration with industrial partners and a case study from defence sector and the results showed that the affordability system is capable of providing a good assessment of customer affordability.

Even though it is an attractive strategy, Mass customization (MC) is not feasible in all environments, and when it is it presents many challenges to be dealt with. Although the literature presents many methods for implementing MC, none of these propose a structured way for implementing and evaluating such a strategy as a whole, each concentrated on one department or phase of the supply or value chains. In the paper, "Extended Value network modelling and simulation for mass customization implementation" Daaboul et al., considers the 3 main steps of implementing of $\mathrm{MC}$ as a strategy in a company: deciding on the customization offer and the desired level of MC, planning for the change induced in the whole enterprise by such a strategy, and finally evaluating the implemented strategy and constantly improving it. They suggest in the paper the use of extended value network 
modelling and simulation for the second and third steps of MC implementation.

The guest editorial team would like to thank all the authors for the time and effort in contributing their papers and in incorporating the referees' comments in revising their manuscripts. Thanks are especially extended to the referees in giving their valuable comments to the papers, which are most essential for this Special Issue to come into being. Guest editors are grateful to Springer, the publisher of DET2009 Proceedings, for giving permission to extend the papers for this special issue. Finally, the guest editors would like to express their thanks to Professor Andrew Kusiak (Editor-inChief) and the Journal Office for their advice and supports that make this Special Issue project a success.

Open Access This article is distributed under the terms of the Creative Commons Attribution Noncommercial License which permits any noncommercial use, distribution, and reproduction in any medium, provided the original author(s) and source are credited. 